\title{
Glutamate Triggers Rapid Glucose Transport Stimulation in Astrocytes as Evidenced by Real-Time Confocal Microscopy
}

\author{
Anitsi Loaiza, Omar H. Porras, and Luis Felipe Barros \\ Centro de Estudios Científicos, Casilla 1469, Valdivia, Chile
}

\begin{abstract}
Glutamate stimulates glycolysis in astrocytes, a phenomenon that couples astrocytic metabolism with neuronal activity. However, it is not known whether glutamate also affects glucose transporter-1 (GLUT1), the transporter responsible for glucose entry into astrocytes. To address this question, two different real-time single-cell hexose uptake assays were applied to cultured hippocampal astrocytes using confocal epifluorescence microscopy. Glutamate caused a twofold to threefold increase in the zero-trans uptake rates of the fluorescent hexoses 2-[N-(7-nitrobenz-2-oxa-1,3-diazol-4-yl)amino]-2-deoxyglucose (2-NBDG) and 6-[N-(7-nitrobenz-2-oxa-1,3-diazol-4yl)amino]-6-deoxyglucose (6-NBDG). Galactose uptake, determined by the calcein volumetric assay, was stimulated to a similar extent, confirming the fluorescent hexose data, and also demonstrating that glutamate stimulation is a $V_{\max }$ effect. Remarkably, glucose transport stimulation developed fully inside $10 \mathrm{sec}$, which is 100 times faster than acute stimulations of glucose transport in other cell types. Glutamate did not significantly affect the rate of 6-NBDG uptake by GLUT1-expressing epithelial Clone 9 cells, suggesting that an astrocyte-specific factor is required for transport stimulation. We conclude that glucose transport stimulation occurs early during astrocytic activation by glutamate, which provides a novel regulatory node to current models of brain energy metabolism. This mechanism should also be considered for the interpretation of functional imaging data based on hexoses.
\end{abstract}

Key words: glucose; galactose; membrane transport; 2-NBDG; 6-NBDG; calcein

\section{Introduction}

Acute exposure to glutamate causes a twofold increase in hexose utilization by cultured astrocytes, a mechanism that is pivotal in the model of neuron-astrocyte metabolic coupling first advanced by Pellerin and Magistretti (1994). According to their lactate shuttle hypothesis, glutamate released by neurons during synaptic activity activates the production of lactate from glucose in astrocytes. Lactate is then used by neurons to generate ATP, which in turn, fuels synaptic activity, thus closing the cycle (Magistretti et al., 1999; Sokoloff, 1999; Pellerin and Magistretti, 2003). Stimulation of astrocytic glycolysis was shown to be sensitive to cytochalasin B, demonstrating first that the main source of glucose is extracellular, as opposed to endogenous glycogen (Pellerin and Magistretti, 1994), and second, that glucose permeates the astrocytic cell membrane using a glucose transporter. Because GLUT1 is the only isoform of the glucose transporter expressed in cortical astrocytes (Vannucci et al., 1997), it is clear that the stimulation of glycolysis by glutamate requires previous permeation of the sugar via GLUT1, which in the current model, would play a permissive role.

Received April 16, 2003; revised May 30, 2003; accepted June 3, 2003.

This work was funded by Fondecyt 1020648. Institutional support to the Centro de Estudios Científicos (CECS) from Empresas Compañía Manufacturera de Papeles y Cartones is gratefully acknowledged. CECS is a Millennium Science Institute and is funded in part by grants from Fundación Andes and the Tinker Foundation. We thank Timothy Ryan and Arle Kruckeberg for helpful discussions and Steve A. Baldwin for GLUT1 antisera. We thank Karen Everett for critically reading this manuscript.

Correspondence should be addressed to Dr. Luis Felipe Barros, Centro de Estudios Científicos, Casilla 1469, Valdivia, Chile. E-mail: fbarros@cecs.cl.

Copyright $\odot 2002$ Society for Neuroscience $\quad$ 0270-6474/02/227337-06\$15.00/0
In other cell systems, however, glycolytic stimulation is accompanied or preceded by active stimulation of glucose transport. GLUT1 is modulated by metabolic stress, as reported by several groups, including our own (Baldwin et al., 1997; Hamrahian et al., 1999). For instance, GLUT1 in Clone 9 epithelial cells responds to metabolic stress by an increase in its intrinsic activity, which may be mediated by the AMP-activated protein kinase AMPK (Barnes et al., 2002). In these cells, the activity of GLUT1 is also acutely modulated by the cytosolic concentration of calcium (Quintanilla et al., 2000).

Here, we describe two real-time hexose uptake assays and their application to mixed hippocampal cultures to explore possible changes in sugar uptake associated with the phenomenon of glutamate-stimulated glycolysis. The first assay measured the uptake of the slowly transported fluorescent hexoses 2-[N-(7-nitrobenz-2-oxa-1,3-diazol-4-yl)amino]-2-deoxyglucose (2-NBDG) and 6-[N-(7-nitrobenz-2-oxa-1,3-diazol-4-yl)amino]-6-deoxyglucose (6-NBDG). The second assay recorded the swelling that occurs when galactose and osmotically obliged water enter the astrocytes under isotonic conditions. Both methods showed that exposure of astrocytes to glutamate results in rapid hexose transport stimulation, a phenomenon that adds a regulatory node to the current model of neuronal-astrocytic metabolic coupling, and also represents the fastest modulation of glucose transporters so far reported.

\section{Materials and Methods}

Materials. Fura-red, calcein-AM, the hexoses 2-NBDG and 6-NBDG, and pluronic acid were obtained from Molecular Probes (Eugene, OR). 
Tissue culture reagents and standard chemicals were from Sigma (St. Louis, MO). Anti-GFAP was from Dako (Hamburg, Germany), FITCconjugated and peroxidase-conjugated secondary antibodies were from Sigma.

Cell culture and immunodetection. Sprague Dawley rats were obtained from the Universidad Austral de Chile. Mixed cultures of neuronal and glial cells were prepared from 1- to 3-d-old neonatal rats as described previously (Alvarez et al., 1999). Cells were initially plated in MEM-10\% fetal bovine serum media and maintained at $37^{\circ} \mathrm{C}$ in a humid atmosphere with 5\% $\mathrm{CO}_{2}$ and $95 \%$ air. Two hours after plating, media were replaced by serum-free N1-MEM (MEM supplemented with $750 \mathrm{mg} / \mathrm{ml}$ glucose, $100 \mu \mathrm{m}$ putrescine, $20 \mathrm{~nm}$ progesterone, $30 \mathrm{~nm}$ selenium dioxide, $100 \mu \mathrm{g}$ of transferrin, $5 \mu \mathrm{g} / \mathrm{ml}$ insulin, $1 \mathrm{~mm}$ sodium pyruvate, and $0.1 \%$ ovalbu$\mathrm{min})$. A total of $10^{5}$ cells were plated on $1 \mathrm{mg} / \mathrm{ml}$ poly-L-lysine-coated coverslips $(25 \mathrm{~mm})$. One-half of the culture media (N1-MEM) was removed and replaced with new media $4 \mathrm{~d}$ after plating. Cells were used for experiments within $10 \mathrm{~d}$ of being cultured. Immunocytochemistry and immunoblotting were performed using standard procedures described in detail previously (Barros et al., 1995). Paraformaldehyde-fixed cells were stained with affinity-purified anti-peptide antibodies at $0.05 \mu \mathrm{g} / \mathrm{ml}$ (GLUT1) or $4 \mu \mathrm{g} / \mathrm{ml}$ (GFAP). Immunoblots were stained with 0.05 $\mu \mathrm{g} / \mathrm{ml}$ GLUT1 antibody. Clone 9 cells were cultured as described previously (Barros et al., 1995).

Confocal microscopy. For single-cell uptake assays and immunocytochemistry, cells were imaged using an inverted Zeiss (Jena, Germany) LSM 5 Pascal laser scanning confocal microscope with $40 \times$ [numerical aperture (NA), 1.3] or $63 \times(\mathrm{NA}, 1.4)$ objectives. The pinhole was set to produce optical sections thinner than $2 \mu \mathrm{m}$. Control experiments showed that under our experimental conditions, dye bleaching was negligible.

Single-cell fluorescent hexose uptake assay. The uptake of the fluorescent hexoses 2-NBDG and 6-NBDG was assayed at room temperature (23$26^{\circ} \mathrm{C}$ ) in real time by a modification of methods used previously in other mammalian cells (Lloyd et al., 1999; Yamada et al., 2000; Roman et al., 2001; Ball et al., 2002). Before transport measurements, culture medium was removed and coverslips were washed with Krebs'-Ringer HEPES (KRH) buffer, containing the following (in mM): $136 \mathrm{NaCl}, 20$ HEPES, $4.7 \mathrm{KCl}, 1.25 \mathrm{MgSO}_{4}$, and $1.25 \mathrm{CaCl}_{2}, \mathrm{pH} 7.4$, supplemented with 3.3-5 glucose $(\mathrm{KRH}-\mathrm{glc})$. For some experiments, cells were then loaded for 30 min with $5 \mu \mathrm{M}$ fura red-AM. This allowed semiquantitative tracking of intracellular calcium during hexose uptake assays. Five minutes before uptake, glucose in the medium was reduced to $0.5 \mathrm{~mm}$ to minimize competition with dye transport. Uptake was started by addition of 300 $\mu \mathrm{M}$ 2-NBDG or 6-NBDG, the concentration chosen as the minimum capable of giving an adequate signal/noise ratio. Cultures were excited at $488 \mathrm{~nm}$; 2-NBDG and 6-NBDG were imaged at 505-550 $\mathrm{nm}$ emission, and fura red was imaged simultaneously at $>585 \mathrm{~nm}$ emission. Intracellular hexose concentration was calculated by comparing intracellular fluorescence with the signal outside the cells. Because of the broad emission spectra of the hexoses, some spillover of their fluorescence into the red channel was unavoidable but still allowed accurate detection of calcium transients with the dye.

Single-cell volumetric hexose uptake assay. The uptake of galactose was measured at room temperature $\left(23-26^{\circ} \mathrm{C}\right)$. The method exploits cell volume changes that occur during hexose uptake, and has been described extensively in a previous paper on epithelial cells (Barros, 1999). In its application to cultured astrocytes, some changes were introduced. Briefly, cells were loaded for 5 min with $5 \mu \mathrm{M}$ calcein-AM in KRH-glc containing $0.02 \%$ pluronic acid. After fluorescence had reached a plateau $(10-20 \mathrm{~min})$, glucose in the medium was reduced to $0.5 \mathrm{~mm}$, and $100 \mathrm{~mm}$ $\mathrm{NaCl}$ of the buffer was isotonically replaced by $200 \mathrm{~mm}$ mannitol. Uptake was started by replacing the mannitol with $200 \mathrm{~mm}$ galactose. This protocol of isotonic galactose uptake helped to minimize stress to the cells before uptake assays. After each experiment, reversibility was checked by replacement of galactose with mannitol. Fluorescence data were translated into uptake data using the following equation: [galactose $]_{i(t)}=200$ $\mathrm{mm} \times\left(1-F_{(t)}\right) /\left(1-F_{\min }\right)$, where [galactose $_{i(t)}$ is the intracellular concentration of the sugar at time $t, F_{(t)}$ is fluorescence at time $t$, and $F_{\text {min }}$ is the minimum fluorescence calculated from the osmometric re- sponse curve (see Fig. 2B). Control experiments indicated (data not shown) that: (1) an uptake assay per se did not affect the rate of galactose uptake in a second assay performed $10 \mathrm{~min}$ later in the same cells; (2) under our experimental conditions, astrocytes showed neither a regulatory volume decrease nor a regulatory volume increase; and (3) no detectable changes in cell volume were measured by exposure of astrocytes to glutamate.

Statistical analysis. Nonlinear regression analyses were performed with the computer program SigmaPlot (Jandel Scientific, Corte Madera, CA). Data are presented as mean \pm SEM (number of cells). Statistical significance was assessed using Student's paired $t$ test. Significance was taken at $p<0.05$.

\section{Results}

\section{Glutamate stimulates astrocytic glucose transport}

Astrocytes in hippocampal cultures were identified by their flat, extended appearance, often reaching $80 \mu \mathrm{m}$ maximum diameter and $6 \mu \mathrm{m}$ height, forming a fenestrated monolayer (Fig. 1 A). Neuronal bodies, which were much more birefringent under phase contrast, were typically $8-10 \mu \mathrm{m}$ in diameter and were most often located on top of the astrocytic layer (data not shown). The correct morphological identification of astrocytes was confirmed by immunostaining for the specific marker GFAP (Fig. $1 A$ ). In agreement with previous reports (Vannucci et al., 1997), astrocytes were found to express a high concentration of GLUT1 (Fig. 1A) but not GLUT3 (data not shown). Most GLUT1 was found at the cell surface, evidenced by both strong staining of microvilli and cell processes and lack of perinuclear staining, which can be contrasted with the intracellular pattern characteristic of GFAP. The location of the transporter at the cell surface is in agreement with previous studies in cultured astrocytes (Vannucci et al., 1997) but differs with its distribution in several cell lines, such as 3T3-L1 fibroblasts and Clone 9 cells, in which part of the GLUT1 pool is intracellular.

During exposure of astrocytes to 2-NBDG, the dye accumulated in the cells at a constant rate averaging $32 \pm 3 \mathrm{~nm} / \mathrm{sec}(50$ cells in seven experiments). As expected from the strong presence of GLUT1 in these cells and from previous work with the dye in other cell types (Lloyd et al., 1999; Yamada et al., 2000; Roman et al., 2001; Ball et al., 2002), uptake was inhibited $66 \pm 6 \%$ (19 cells; $n=3$ experiments; $p<0.05$ ) by $20 \mu \mathrm{M}$ cytochalasin B. Intracellular sugar concentration during initial uptake assays did not reach $>20 \%$ of that outside the cells, so it was assumed that uptake rates reflect the transporter acting under near zero-trans conditions (Quintanilla et al., 2000). This is important, because zero-trans uptake is determined solely by transport efficiency, with eventual changes in the phosphorylation step being negligible.

Exposure of astrocytes to glutamate caused a sharp increase in the rate of 2-NBDG uptake (Fig. $1 B$ ). In eight experiments with 50 astrocytes, stimulation was variable, averaging $111 \pm 25 \%$ $(p<0.05)$, with a maximum of $1400 \%$. Typically, $30-60 \%$ of astrocytes present in a given microscopic field responded to glutamate, with a maximum degree of stimulation registered between 7 and $10 \mathrm{~d}$ of culture. Similar results were obtained with 6-NBDG (Fig. 1C), a substrate of GLUT1 (Speizer et al., 1985) that is not metabolized by brain cells (Shimada et al., 1994), with glutamate increasing the rate of uptake by $178 \pm 78 \%(p<0.05)$ from its basal rate of $85 \pm 22 \mathrm{~nm} / \mathrm{sec}$ ( $n=14$ cells in four experiments). This confirms that a change in transport and not phosphorylation accounts for uptake stimulation. Again, $\sim 50 \%$ of the astrocytes present in the field reacted to glutamate with a stimulation of hexose uptake. In summary, experiments with both 
A

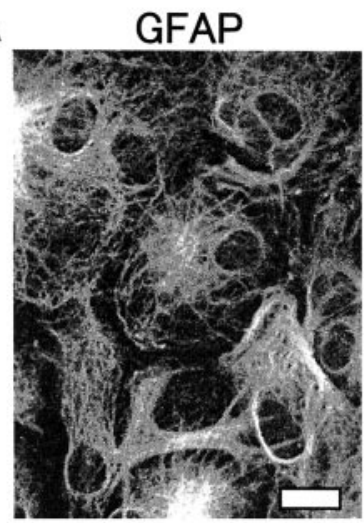

B

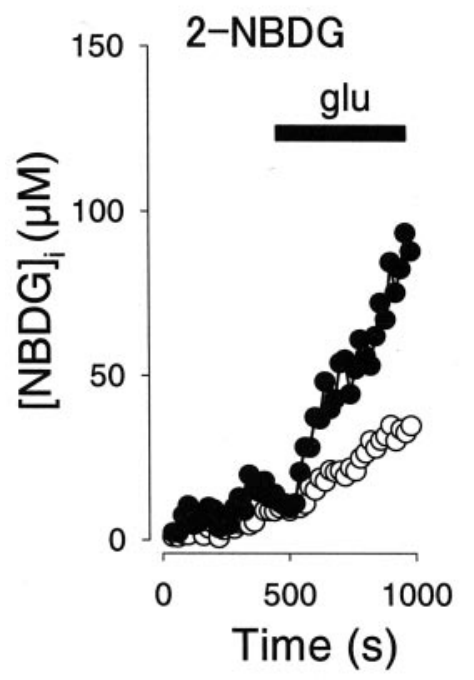

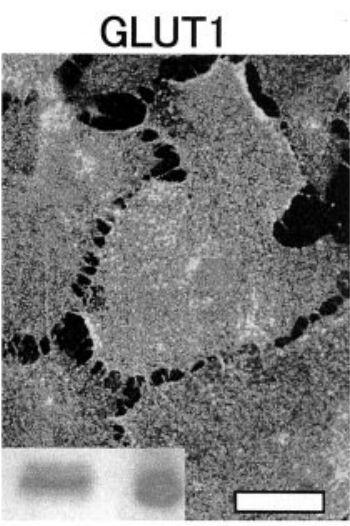

C

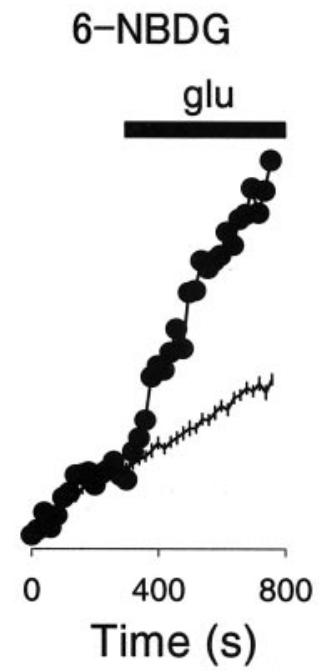

Figure 1. Glutamate stimulates the uptake of fluorescent hexoses by single hippocampal astrocytes. $A$, Cells were stained with antibodies against GFAP (left) or GLUT1 (right) and then imaged by confocal microscopy, as described in Materials and Methods. Scale bars, $20 \mu \mathrm{m}$. The inset shows GLUT1 immunodetected in $50 \mu \mathrm{g}$ of total hippocampal proteins (left) and $50 \mathrm{ng}$ of human erythrocyte membranes (right). B, Intracellular 2-NBDG was measured in two neighboring astrocytes during continuous exposure to $300 \mu \mathrm{m}$ extracellular sugar. At the time indicated, $0.5 \mathrm{~mm}$ glutamate (glu) was added to the cells, resulting in different degrees of stimulation. $C$, Intracellular 6-NBDG was measured in a single astrocyte during continuous exposure to $300 \mu \mathrm{m}$ extracellular sugar (filled symbols). At the time indicated, $0.5 \mathrm{~mm}$ glutamate was added. Data from 20 nonstimulated control cells are shown for comparison (mean \pm SEM).

probes demonstrated that glutamate causes rapid stimulation of hexose transport via astrocytic GLUT1 carriers. In control experiments in Clone 9 cells, which, like astrocytes, only express GLUT1, 0.5 mm glutamate did not stimulate 6-NBDG uptake but caused a slight although nonsignificant inhibition of $22 \pm 15 \%$ $(n=14$ cells in three experiments; $p>0.05)$, indicating that GLUT1 stimulation by glutamate requires a factor specific for astrocytes.

As an independent approach to corroborate the phenomenon, we applied to astrocytes the other available protocol that allows real-time estimation of hexose transport in single cells (Barros, 1999). Because of the presence of the poly-L-lysine substrate that was found to respond to changes in osmolarity, a modification to measure sugar transport under isotonic conditions

A
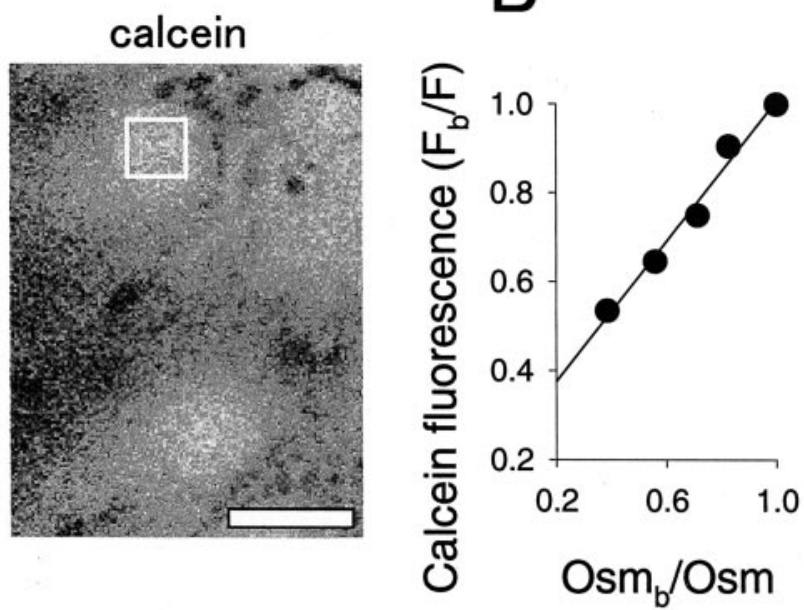

C

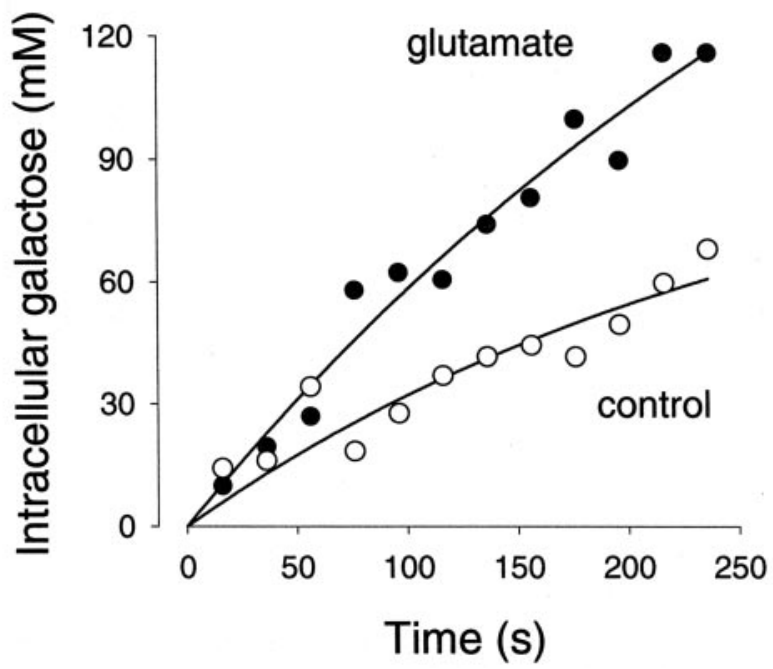

Figure 2. Glutamate stimulates the uptake of galactose by single hippocampal astrocytes. $A$, Confocal section of astrocytes loaded with calcein. The cell for which galactose uptake curves are depicted in C is indicated with a white square. Scale bar, $20 \mu \mathrm{m}$. B, Calcein fluorescence was measured in cells exposed to KRH plus increasing concentrations of extracellular mannitol (final osmolarities of $285,345,400,510$, and $740 \mathrm{~m} 0 \mathrm{sm})$. Relative fluorescence is plotted against relative osmolarity with $F_{\mathrm{b}} / F=0.79 \times 0 \mathrm{sm}_{\mathrm{b}} / 0 \mathrm{sm}+0.22 ; r=0.98$. C, Uptake was estimated from galactose-induced changes in calcein fluorescence in the cell boxed in $A$ before and $10 \mathrm{~min}$ after exposure to $0.5 \mathrm{~mm}$ glutamate. Initial rates, calculated by fitting two-parameter single exponential functions to the data, were 0.38 and $0.66 \mathrm{~mm} / \mathrm{sec}$ for basal and stimulated uptake, respectively.

was devised, which is described in Materials and Methods. Astrocytes were found to load homogenously with calcein, and displayed a sensitive osmometric response to mannitol, indicative of low compartmentalization of the dye (Fig. $2 A, B$ ). The initial rate of galactose uptake by astrocytes was estimated at $0.9 \pm 0.4 \mathrm{~mm} /$ $\sec (n=41$ cells $)$ and was inhibited $88 \pm 24 \%(n=8$ cells; $p<$ 0.05 ) by $20 \mu \mathrm{M}$ cytochalasin B, supporting GLUT1 involvement. Figure $2 C$ shows that the astrocytic rate of galactose uptake was stimulated by $0.5 \mathrm{~mm}$ glutamate, thus confirming by an unrelated method the result obtained with fluorescent hexoses. In five separate experiments that included 25 astrocytes, glutamate induced a significant stimulation of galactose uptake in 10 of the cells, averaging $100 \pm 23 \%(p<0.05)$. 
Because at this high concentration, galactose nearly saturates GLUT1 (Ginsburg and Stein, 1975), this experimental protocol provides a direct evaluation of the $V_{\max }$ for zero-trans uptake (Barros, 1999). The stimulatory effect of glutamate can therefore be considered a $V_{\max }$ effect.

\section{Glucose transport stimulation by glutamate is fast}

Having demonstrated by two independent methods that glutamate stimulates hexose uptake by astrocytes, we next used the fluorescent hexose assay to estimate how fast the effect can be. It has been shown previously that glutamate causes an increase in astrocytic free calcium within $3 \mathrm{sec}$ (Glaum et al., 1990). To detect the calcium signal, uptake assays were performed with cells preloaded with the fast reciprocal calcium dye fura-red, and the time that glutamate first reached the cell was computed from the first sharp deflection of the signal. Taking advantage of the linear behavior of uptake both before and after glutamate addition, a graphical procedure was devised to estimate the onset of uptake stimulation. This was done by solving the equation system formed by the linear uptake curves before and after glutamate addition (Fig. 3). For 10 astrocytes in six separate experiments, the delay between detection of the calcium increase and transport stimulation was $9 \pm 3 \mathrm{sec}$.

\section{Discussion}

We report that glutamate stimulates hexose transport in astrocytes. Because GLUT1 is the only isoform of the glucose transporter present in these cells, the effect can therefore be directly ascribed to stimulation of GLUT1. We also report that stimulation occurs in the range of a few seconds, which makes this phenomenon the fastest stimulation of mammalian glucose transport yet known. This paper also presents two new methods for real-time measurement of sugar transport in single astrocytes.

The single-cell approach was essential for the study of mixed cultures, because standard isotope-based methods require homogeneous cell populations, and also because radioactively labeled hexoses permeate astrocytes too fast to allow accurate determination of initial transport rates at room temperature. Moreover, isotopic techniques require destruction of the cells for each data point, precluding the design of "before-and-after" experiments. The relatively low rate of 2-NBDG and 6-NBDG uptake by astrocytes is consistent with results in other cell types. For instance, in GLUT1-expressing human erythrocytes, the transport of $6-\mathrm{NBDG}$ at $24^{\circ} \mathrm{C}$ was 3300 -fold slower than the transport of methyl-D-glucose at $4^{\circ} \mathrm{C}$ (Cloherty et al., 1995). The poor permeation of the NBDGs into astrocytes was an important advantage, because it made it possible to determine uptake rates under zero-trans conditions at room temperature, allowing detection of acute changes during experimental interventions. The phenomenon of GLUT1 stimulation by glutamate was reproduced using galactose as permeant sugar, confirming that the phenomenon is reproducible with other substrates of GLUT1. Incidentally, the basal rate of galactose uptake by astrocytes was three to four times faster than that of HeLa cells and human erythrocytes, cells conspicuous for their very high glucose transport capacity (Ginsburg and Stein, 1975; Barros, 1999). The $K_{\mathrm{m}}$ for 6-NBDG uptake by GLUT1 has been estimated in the millimolar range (Speizer et al., 1985). At the $300 \mu \mathrm{M}$ concentration used in this work, transport is therefore essentially proportional to $V_{\max } / K_{\mathrm{m}}$, and changes in either of these kinetic parameters may in principle have accounted for the stimulation. In vivo, the situation is similar, with

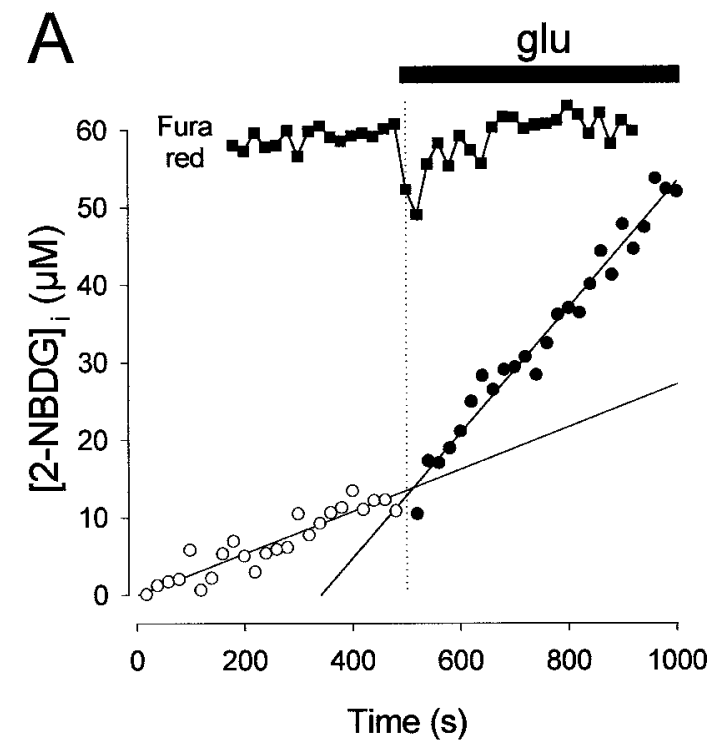

B

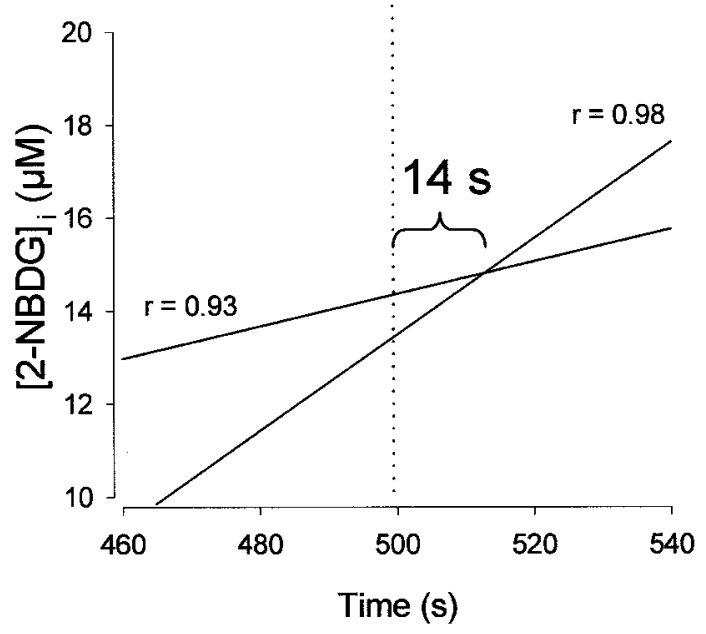

Figure 3. Astrocytic glucose transport stimulation occurs within seconds. $A$, Intracellular calcium was recorded simultaneously with 2-NBDG uptake to correlate the onset of the effect of glutamate (glu) on both parameters. Note that fura-red emission varies reciprocally with intracellular calcium. Linear equations were fitted by nonlinear regression to the data before (open symbols) and after (filled symbols) addition of $0.5 \mathrm{~mm}$ glutamate. $B$, Magnification of $A$ to illustrate the relative positions of the intercept between the regression curves and the first detection of calcium increase. For this astrocyte, the delay was estimated at $14 \mathrm{sec}$.

GLUT1 operating near or below its $K_{\mathrm{m}}$ for transport; thus, at a fixed concentration of glucose, an increase in uptake may in principle be achieved by lowering $K_{\mathrm{m}}$ or by increasing $V_{\max }$. The second method applied, which was developed in our laboratory to study HeLa cells and GLUT1-expressing Clone 9 cells (Barros, 1999), involved hexose concentrations that saturate $\sim 95 \%$ of the transport sites, considering the $K_{\mathrm{m}}$ for zero-trans galactose uptake at $11 \mathrm{~mm}$ (Ginsburg and Stein, 1975), thus providing direct reporting of the $V_{\max }$. Because galactose uptake was increased by glutamate to a similar extent as the rate of zero-trans NBDG uptake, it can be concluded that a significant part of the neurotransmitter effect is a $V_{\max }$ effect.

The biochemical mechanisms underlying the stimulation of GLUT1 by glutamate are currently under investigation. One candidate is sodium-induced metabolic stress, because glycolytic ac- 
tivation critically requires sodium entry through glutamate carriers followed by its extrusion by $\mathrm{Na}^{+}-\mathrm{K}^{+}$ATPase (Pellerin and Magistretti, 1997; Chatton et al., 2000; Voutsinos-Porche et al., 2003). A recent report shows that cultured hippocampal astrocytes from the mouse can be segregated into two morphologically indistinguishable populations: one that expresses glutamate carriers and one that expresses glutamate receptors (Matthias et al., 2003). It is possible that the heterogeneity observed in glucose transport may also be related to the existence of two astrocytic subpopulations. Other candidate mechanisms that may account for the effect of glutamate are the multiple signaling pathways that mediate GLUT1 stimulation by stress in other cell types. These include calcium (Quintanilla et al., 2000), the AMPactivated protein kinase AMPK (Abbud et al., 2000; Barnes et al., 2002), p38MAPK (mitogen-activated protein kinase) (Barros et al., 1997), and phospholipase C (Prasad and Ismail-Beigi, 1999). Notably, all of these signaling pathways and others responding to reagents such as cadmium (Harrison et al., 1991) affect the $V_{\max }$ of glucose transport by augmenting the intrinsic activity of individual carriers (activation). Because most GLUT1 carriers in astrocytes were stained at the cell surface, we believe glutamate stimulation is most likely to result from carrier activation and not from its translocation from intracellular membranes. However, we cannot rule out translocation, because GLUT1 transporters may still be located in membrane vesicles docked near the surface that may fuse with the plasma membrane in response to glutamate. Definite clarification of this issue will require direct measurement of surface carrier density.

The phenomenon reported here also begs the question of physiological significance. Electron microscopy of primate brains has shown that GLUT1 is preferentially located at both functional ends of astrocytes, the feet that surround microvessels and the distal processes that surround the synapses (Morgello et al., 1995). This distribution seems to have functional consequences, because radiolabeled sugar transport into the brain has been correlated with local GLUT1 density, suggesting a limiting role for the carrier (Duelli et al., 2001). In vivo measurements using a glucose microsensor showed that hippocampal stimulation caused a transient decrease in the concentration of interstitial glucose (Hu and Wilson, 1997). Because the use of glucose is intracellular, the observation shows that glucose gradients can be generated between brain cells and their surroundings, with glucose transport becoming rate-limiting for glucose metabolism. Under such conditions, the mechanism reported here may serve a physiological role, much in the same way that insulin-mediated GLUT4 stimulation facilitates glucose utilization by muscle and fat or GLUT1 activation facilitates glucose utilization in stressed cells.

A model has been proposed recently in which astrocytes respond to the metabolic demands of glutamate uptake in fractions of seconds as a result of the rapid degradation of stored glycogen. After glutamate is cleared, astrocytic glycogen is replenished from extracellular glucose (Shulman et al., 2001). Considering its time constant in the order of seconds, GLUT1 stimulation will facilitate preferential access of the sugar into active areas, perhaps facilitating glycogen replenishment. Astrocytic GLUT1 activation would then work in tandem with functional hyperemia, a response that also develops in the order of a few seconds, to increase the delivery of glucose to active brain areas. Notably, functional hyperemia has been ascribed recently to the effects of glutamate on astrocytes (Zonta et al., 2003). Finally, glucose transport stimula- tion such as that observed here could further subserve the activation of glycolysis by glutamate demonstrated previously in this cell type (Pellerin and Magistretti, 1994).

\section{References}

Abbud W, Habinowski S, Zhang JZ, Kendrew J, Elkairi FS, Kemp BE, Witters LA, Ismail-Beigi F (2000) Stimulation of AMP-activated protein kinase (AMPK) is associated with enhancement of Glut1-mediated glucose transport. Arch Biochem Biophys 380:347-352.

Alvarez A, Toro R, Caceres A, Maccioni RB (1999) Inhibition of tau phosphorylating protein kinase $c \mathrm{dk} 5$ prevents beta-amyloid-induced neuronal death. FEBS Lett 459:421-426.

Baldwin SA, Barros LF, Griffiths M, Ingram J, Robbins EC, Streets AJ, Saklatvala J (1997) Regulation of GLUT1 in response to cellular stress. Biochem Soc Trans 25:954-958.

Ball SW, Bailey JR, Stewart JM, Vogels CM, Westcott SA (2002) A fluorescent compound for glucose uptake measurements in isolated rat cardiomyocytes. Can J Physiol Pharmacol 80:205-209.

Barnes K, Ingram JC, Porras OH, Barros LF, Hudson ER, Fryer LG, Foufelle F, Carling D, Hardie DG, Baldwin SA (2002) Activation of GLUT1 by metabolic and osmotic stress: potential involvement of AMP-activated protein kinase (AMPK). J Cell Sci 115:2433-2442.

Barros LF (1999) Measurement of sugar transport in single living cells. Pflügers Arch 437:763-770.

Barros LF, Yudilevich DL, Jarvis SM, Beaumont N, Young JD, Baldwin SA (1995) Immunolocalisation of nucleoside transporters in human placental trophoblast and endothelial cells: evidence for multiple transporter isoforms. Pflügers Arch 429:394-399.

Barros LF, Young M, Saklatvala J, Baldwin SA (1997) Evidence of two mechanisms for the activation of the glucose transporter GLUT1 by anisomycin: p38(MAP kinase) activation and protein synthesis inhibition in mammalian cells. J Physiol (Lond) 504:517-525.

Chatton JY, Marquet P, Magistretti PJ (2000) A quantitative analysis of L-glutamate-regulated $\mathrm{Na}^{+}$dynamics in mouse cortical astrocytes: implications for cellular bioenergetics. Eur J Neurosci 12:3843-3853.

Cloherty EK, Sultzman LA, Zottola RJ, Carruthers A (1995) Net sugar transport is a multistep process. Evidence for cytosolic sugar binding sites in erythrocytes. Biochemistry 34:15395-15406.

Duelli R, Maurer MH, Staudt R, Sokoloff L, Kuschinsky W (2001) Correlation between local glucose transporter densities and local 3-Omethylglucose transport in rat brain. Neurosci Lett 310:101-104.

Ginsburg H, Stein WD (1975) Zero-trans and infinite-cis uptake of galactose in human erythrocytes. Biochim Biophys Acta 382:353-368.

Glaum SR, Holzwarth JA, Miller RJ (1990) Glutamate receptors activate $\mathrm{Ca}^{2+}$ mobilization and $\mathrm{Ca}^{2+}$ influx into astrocytes. Proc Natl Acad Sci USA 87:3454-3458.

Hamrahian AH, Zhang JZ, Elkhairi FS, Prasad R, Ismail-Beigi F (1999) Activation of Glutl glucose transporter in response to inhibition of oxidative phosphorylation. Arch Biochem Biophys 368:375-379.

Harrison SA, Buxton JM, Clancy BM, Czech MP (1991) Evidence that erythroid-type glucose transporter intrinsic activity is modulated by cadmium treatment of mouse 3T3-L1 cells. J Biol Chem 266:19438-19449.

Hu Y, Wilson GS (1997) Rapid changes in local extracellular rat brain glucose observed with an in vivo glucose sensor. J Neurochem 68:1745-1752.

Lloyd PG, Hardin CD, Sturek M (1999) Examining glucose transport in single vascular smooth muscle cells with a fluorescent glucose analog. Physiol Res 48:401-410.

Magistretti PJ, Pellerin L, Rothman DL, Shulman RG (1999) Energy on demand. Science 283:496-497.

Matthias K, Kirchhoff F, Seifert G, Huttmann K, Matyash M, Kettenmann H, Steinhauser C (2003) Segregated expression of AMPA-type glutamate receptors and glutamate transporters defines distinct astrocyte populations in the mouse hippocampus. J Neurosci 23:1750-1758.

Morgello S, Uson RR, Schwartz EJ, Haber RS (1995) The human bloodbrain barrier glucose transporter (GLUT1) is a glucose transporter of gray matter astrocytes. Glia 14:43-54.

Pellerin L, Magistretti PJ (1994) Glutamate uptake into astrocytes stimulates aerobic glycolysis: a mechanism coupling neuronal activity to glucose utilization. Proc Natl Acad Sci USA 91:10625-10629.

Pellerin L, Magistretti PJ (1997) Glutamate uptake stimulates $\mathrm{Na}^{+}, \mathrm{K}^{+}$. ATPase activity in astrocytes via activation of a distinct subunit highly sensitive to ouabain. J Neurochem 69:2132-2137. 
Pellerin L, Magistretti PJ (2003) How to balance the brain energy budget while spending glucose differently. J Physiol (Lond) 546:325.

Prasad RK, Ismail-Beigi F (1999) Mechanism of stimulation of glucose transport by $\mathrm{H}_{2} \mathrm{O}_{2}$ : role of phospholipase C. Arch Biochem Biophys 362:113-122.

Quintanilla RA, Porras OH, Castro J, Barros LF (2000) Cytosolic $\left[\mathrm{Ca}^{2+}\right]$ modulates basal GLUT1 activity and plays a permissive role in its activation by metabolic stress and insulin in rat epithelial cells. Cell Calcium 28:97-106.

Roman Y, Alfonso A, Louzao MC, Vieytes MR, Botana LM (2001) Confocal microscopy study of the different patterns of 2-NBDG uptake in rabbit enterocytes in the apical and basal zone. Pflügers Arch 443:234-239.

Shimada M, Kawamoto S, Hirose Y, Nakanishi M, Watanabe H, Watanabe M (1994) Regional differences in glucose transport in the mouse hippocampus. Histochem J 26:207-212.

Shulman RG, Hyder F, Rothman DL (2001) Cerebral energetics and the glycogen shunt: neurochemical basis of functional imaging. Proc Natl Acad Sci USA 98:6417-6422.
Sokoloff L (1999) Energetics of functional activation in neural tissues. Neurochem Res 24:321-329.

Speizer L, Haugland R, Kutchai H (1985) Asymmetric transport of a fluorescent glucose analogue by human erythrocytes. Biochim Biophys Acta 815:75-84.

Vannucci SJ, Maher F, Simpson IA (1997) Glucose transporter proteins in brain: delivery of glucose to neurons and glia. Glia 21:2-21.

Voutsinos-Porche B, Bonvento G, Tanaka K, Steiner P, Welker E, Chatton JY, Magistretti PJ, Pellerin L (2003) Glial glutamate transporters mediate a functional metabolic crosstalk between neurons and astrocytes in the mouse developing cortex. Neuron 37:275-286.

Yamada K, Nakata M, Horimoto N, Saito M, Matsuoka H, Inagaki N (2000) Measurement of glucose uptake and intracellular calcium concentration in single, living pancreatic beta-cells. J Biol Chem 275:22278-22283.

Zonta M, Angulo MC, Gobbo S, Rosengarten B, Hossmann KA, Pozzan T, Carmignoto G (2003) Neuron-to-astrocyte signaling is central to the dynamic control of brain microcirculation. Nat Neurosci 6:43-50. 